\title{
中国核安全法律制度的构建与完善: 初步分析
}

\author{
胡帮达 ${ }^{(1)}$, 汪劲 ${ }^{(1)}$ ，吴岳雷 ${ }^{2}$ \\ (1) 北京大学法学院核政策与法律研究中心, 北京 100871 ; \\ (2) 环境保护部核与辐射安全中心, 北京 100089 \\ *E-mail: wangjin_law@pku.edu.cn \\ 收稿日期: 2013-11-25; 接受日期: 2014-01-03 \\ 教育部人文社会科学研究一般项目(批准号: 11YJA820067)资助项目
}

\begin{abstract}
摘要核安全法律制度是确保核能安全发展的必要手段。国际层面对核安全法律制度构建的 要求和建议可以归纳为八项主要的核安全法律制度. 各国都在法律的层面通过不同的立法模式 构建了这些制度, 然而我国核安全法律制度却存在诸多不足, 亟待完善. 对此, 本文认为: 我国 核安全法律制度的构建具有制定法律的必要性和紧迫性; 核安全法律制度构建应该走多元化立 法的路径; 核安全法应规定核安全监管制度、核安全许可制度、辐射防护制度和许可证持有人 的安全责任制度，可以考虑规定核应急准备与响应制度和核安全信息公开制度.
\end{abstract}

关键词

核安全 法律制度 立法 监管机构 信息公开

\section{1 引言}

2011 年的日本福岛核事故再次敲响了核安全的 警钟, 也推动了我国核安全法律制度建设的进程. 国 务院于 2012 年 10 月通过的《核安全与放射性污染防 治“十二五”规划及 2020 年远景目标》(简称《核安全 规划》)提出要抓紧研究制订核安全法; 2013 年 10 月 30 日, 全国人大常委会发布了《十二届全国人大常委 会立法规划(共 68 件)》将核安全法列为第二类项目, 即“需要抓紧工作、条件成熟时提请审议的法律草案”, 正式宣布核安全法进入国家立法议程.

核安全法立法是一项系统工程, 其内容重在制 度构建. 核安全法应该构建哪些制度? 这些制度是 否符合履行国际义务的要求? 能否做到如《核安全规 划》所指出的“与国际先进水平保持一致”? 是不是结 合了我国近 30 年核安全法律制度建设的实践? 这些 都是立法起草者迫切需要论证的问题. 本文试图对
此进行一个初步分析，供有关部门参考.

\section{2 核安全法律制度构建的域外经验}

\section{1 核安全法律制度构建的国际要求}

自人类和平利用核能以来，国际社会就开始构 建核安全体制. 三厘岛核事故和切尔诺贝利核事故 发生以后, 核安全在世界范围内受到高度重视, 在国 际原子能机构的敦促与组织下核安全国际体制化管 理的趋势已经形成 ${ }^{[1]}$. 主要表现为由国际原子能机构 制定推行了一系列全球一致的核安全标准, 并推动 缔结了多个核安全方面的国际公约.

\subsection{1 国际公约对核安全法律制度构建的要求}

核安全有关国际公约的主要目标是保障核安全, 即实现正常的运行工况, 防止事故或减轻事故后果, 以保护工作人员、公众和环境免受不正当的辐射危

引用格式: 胡帮达, 汪劲, 吴岳雷. 中国核安全法律制度的构建与完善: 初步分析. 中国科学: 技术科学, 2014, 44: 323-330 Hu B D, Wang J, Wu Y L. Construction and improvement of the nuclear safety legal systems in China: A preliminary analysis (in Chinese). Sci Sin Tech, 2014, 44: 323-330, doi: 10.1360/092013-1182 
害 $^{[2]}$. 这些公约包括《及早通报核事故公约》(1986 年)、《核事故或辐射事故紧急情况援助公约》(1986 年)、《核安全公约》(1994 年)、《乏燃料管理安全和 放射性废物安全管理联合公约》(1997 年, 以下简称 《联合公约》)、《关于核损害的民事责任的维也纳公 约》(1963 年)、《核损害补充公约》(1997 年)和《核 材料实物保护公约修订案》 (2005 年). 除《关于核损 害的民事责任的维也纳公约》与《核损害补充公约》 外, 上述其他公约均对我国生效. 这些公约对核安全 法律制度构建的要求主要可以归结为八项, 即核安 全监管、核安全许可、辐射防护、实物保护、核应急 准备与响应、核安全信息公开、许可证持有人的安全 责任和核损害赔偿责任等制度.

核安全监管的内容是要求国家(政府)应当建立 专门的核安全监管部门, 赋予其监管职权和职责, 确 保其对核安全有关事项进行独立有效的监督管理. 如《核安全公约》第八条的规定“每一缔约方应建立或 指定一个监管机构, 并给予履行其规定责任所需的适 当的权力、职能和财政与人力资源; 每一缔约方应采 取适当步骤确保将监管机构的职能与参与促进或利用 核能的任何其他机构或组织的职能有效地分开.”

核安全许可是指在核能开发利用过程中, 禁止 未经核安全监管部门许可从事与核安全相关的活动 (行为).《核安全公约》第七条和《联合公约》第十九 条都规定, 许可证制度内容包括对设施和活动实施 许可、禁止无许可的设施和活动、对许可证人是否遵 守许可的检查以及对许可证条款的强制执行, 包括 中止、修改和吊销许可证.

辐射防护的内容包括保护人员免受电离辐射 照射的影响和实现这种保护的方法 ${ }^{[2]}$.《核安全公约》 第十五条 “辐射防护” 要求确保由核设施引起的对 工作人员和公众的辐射照射量在各种运行状态下保 持在合理可行尽量低的水平, 并确保任何个人受到 的辐照剂量不超过本国规定的剂量限值. 《联合公约》 第二十四条“运行辐射防护”在此基础上, 还要求一 旦发生放射性物质无计划或非受控地释入环境的 情况, 即采取合适的纠正措施控制此种释放和减轻 其影响.

实物保护系指对核设施或使用、咜存或运输中的 核材料实施保护措施, 使其免受任何有预谋的蓄意 破坏的制度. 例如《核材料实物保护公约修订案》认 为，该制度除了支持防止核扩散和反对恐怖主义的
目标以外, 还有利于补充和完善核材料的安全使用、 咜存和运输以及核设施的安全运行.

核应急准备与响应包括为应对核事故做好准备 工作的应急准备, 以及发生或可能发生核事故时采 取控制局势、减轻事故后果、防止或减轻人体受到辐 射损害等措施. 《核安全公约》第十六条和《联合公 约》第二十五条都要求缔约方建立设施的场内和场外 应急计划并定期进行演习. 由于严重的核事故可能 造成跨界影响，《及早通报核事故公约》和《核事故 或辐射紧急情况援助公约》要求在事故紧急状况下缔 约国有国际通报与援助的义务.

核安全信息公开是透明性原则的体现，要求参 与核能开发、利用和监管的所有主体提供核能正在如 何使用的所有相关信息，尤其是有关可能对公众健 康、安全和环境产生影响的事件(事故)和异常情况的 信息. 如 《联合公约》第十三条就规定“对拟议中乏 燃料和放射性废物设施的选址应向公众成员提供此 类设施的安全方面的信息”; 又如《核安全公约》第 十六条规定“每一缔约方应采取适当步骤，以确保可 能受到辐射紧急情况影响的本国居民以及邻近该设 施的国家的主管部门得到制订应急计划和作出应急 响应所需的适当信息.”

许可证持有人的安全责任是指核安全许可证持 有人对其核活动的安全承担主要责任的制度. 由于 核能利用一般涉及多方主体, 如核能的研究与开发 组织、核材料加工商、核设施制造商、建筑工程公司、 施工公司、核设施的运营者、金融机构和监管机构等, 需要确定由谁来负主要的安全责任. 对此, 《核安全公 约》第九条规定“每一缔约方应确保核设施安全的首要 责任由有关许可证的持有者承担，并应采取适当步骤 确保此种许可证的每一持有者履行其责任”; 《联合公 约》第二十一条“许可证持有者的责任”也要求“每一缔 约方应确保乏燃料或放射性废物管理安全的首要责任 由有关许可证的持有者承担，并应采取适当步骤确保 此种许可证的每一持有者履行其责任.”

核损害赔偿责任是一种针对发生核事件或核事 故发生后对人体健康、财产和环境等受到严重损害时 的特殊侵权责任. 该责任制度的构建包括对核损害 的定义、赔偿的范围、责任的承担、赔偿的最高限额、 责任保险、财政保证、追索权、诉讼与管辖等规定. 《关于核损害的民事责任的维也纳公约》和《核损害 补充公约》均对上述内容做出了规定. 


\subsection{2 国际“软法”对核安全法律制度构建的建议}

除了国际公约外, 国际“软法”也对核安全法律 制度构建的要求提出了建议. 国际“软法”指在严格 意义上不具有法律拘束力但又有一定法律效果的国 际组织文件. 国际组织和国际会议上的决议、决定、 宣言、建议和标准等绝大多数都属于这一范畴 ${ }^{[3]}$. 在 核安全领域对各国影响最大的国际“软法”当属国际 原子能机构制定的核安全标准. 到目前为止, 国际原 子能机构已经建立了涵盖铀矿开采与加工、放射性物 质运输、核电站、研究堆、放射源应用、核燃料循环 设施和放射性废物处置的基本安全标准体系. 该标 准体系包括安全基本原则、一般安全要求、一般安全 导则、具体安全要求和具体安全导则等五方面内容. 前三者适用于所有上述七个方面, 后两者则是为落 实前三者的要求根据各领域具体的不同特点而制定 的. 这些标准中的基本安全要素已被载入上述有关 国际公约中, 提供给国际社会使用, 并被各国国内法 所参考 ${ }^{[4]}$. 换言之, 国际原子能机构的核安全标准将 已有的国际公约内容细化, 更富操作性 ${ }^{[5]}$. 此外, 国 际原子能机构为帮助成员国制定核法律而出版的《核 法手册》(2003 年)也对各国核安全法律制度构建具有 参考价值.

除与国际公约在原则上保持一致外，上述安全 标准和《核法手册》的内容更多的是细化了国际公约 的建议和具体要求. 例如, 在关于核安全监管制度方 面, 国际原子能机构的一般安全要求文件一一《促进 安全的政府、法律和监管框架》一一建议各国应建立 核安全监管机构并保持其独立性的同时, 还认为监 管机构应具有对设施和活动的批准、审查和评定安全 相关资料、审查和评定设施或活动的分级方案、视察 设施和活动、制订执法政策、要求受权方采取纠正行 动、与有关各方的交流和磋商等总共二十一项具体的 职权和职责 ${ }^{[6]}$. 又如在核安全许可制度方面, 国际 原子能机构的《核法手册》认为许可证制度应包括许 可证的审批、检查和强制执行, 其中审批部分包括许 可证的适用范围、申请程序、申请人条件与资格、审 批过程中的公众参与、许可证的颁发、中止、修改与 吊销以及对许可证审批决定进行审查; 检查与强制 执行的内容是监管机关检查许可证持有人对许可证 条件的遵守情况和发现不合规行为时采取的强制措 施 ${ }^{[7]}$. 类似地, 国际原子能机构的其他安全标准文件
与《核法手册》分别对其他六项制度的构建给出了详 细建议.

\section{2 各国核安全法律制度构建的实践}

自三厘岛核事故和切尔诺贝利核事故以来, 各 国核立法重点开始向构建和完善核安全法律制度转 移. 在国际层面的倡议和推动下, 国家层面的核安全 立法活动如雨后春笋般地涌现. 归纳起来, 这些国家 的核安全法律制度构建与完善主要表现为通过修改 或制定核能综合法、专门制定核安全法、以及就个别 核安全法律制度单独进行立法这三种模式进行.

\subsection{1 通过修改或制定核能综合法构建或完善核 安全法律制度}

采用这种模式的一部分国家，如俄罗斯、德国、 芬兰、斯洛伐克等，主要通过其综合法规定大部分核 安全法律制度. 以俄罗斯为例, 其《1995 年原子能利 用联邦法》第五章专门规定了核安全监管制度、核安 全许可证制度，其他章节则分别规定了实物保护制 度、核损害赔偿责任制度等. 而另一部分国家如美 国、韩国、匈牙利、澳大利亚等等，在开发利用核能 的早期就制定了核能综合法一一原子能法, 并在该法 中规定了部分核安全法律制度，但有的制度并不健 全，后来修改完善的. 其中典型的就是关于核安全监 管制度的改革, 如《韩国 1958 年原子能法》中的核 安全监管机构的设置方式没有确保其地位的独立性, 1996 年该法被修改时便将核安全委员会从原来的原 子能委员会中分离了出来 ${ }^{[8]}$.

\subsection{2 专门制定核安全法规定核安全法律制度}

通过专门制定核安全法(各国在名称上不尽相同) 来构建核安全法律制度的国家，其核能开发利用程 度差异较大, 但在一定程度上却有较好的代表性. 这 些国家中既有核电大国，如法国、加拿大，又有核电 发展规模很小的国家，如斯洛文尼亚，还包括如澳大 利亚、拉脱维亚、格鲁吉亚、克罗地亚等没有核电的 国家. 根据国际要求对这些国家的核安全法进行梳 理发现: 法国 2006 年《核领域透明与安全法》主要 规定了核安全监管制度、核安全许可制度、核安全信 息公开制度、许可证持有人安全责任制度，并将构建 辐射防护制度与核应急制度作为其监管机构——法 国核安全局的职责; 加拿大 1997 年《核安全与控制 
法》构建了核安全监管制度、核安全许可制度、许可 证持有人的安全责任制度，也把辐射防护制度的构 建作为加拿大核安全委员会的职责之一; 澳大利亚 1998 年《辐射防护与核安全法》和克罗地亚 2003 年 《核安全法》主要规定了核安全监管制度、许可证制 度、辐射防护制度和许可证持有人的安全责任制度; 格鲁吉亚 1998 年《核与辐射安全法》和斯洛文尼亚 2002 年《电离辐射防护与核安全法》都对核安全监 管制度、核安全许可制度、辐射防护制度、实物保护 制度、核安全信息公开制度、核应急准备与响应制度 以及许可证持有人的安全责任制度作出了安排; 而 拉脱维亚 2000 年《辐射安全与核安全法》则涵盖了 全部国际要求中的八项制度.

\subsection{3 为核安全法律制度单独立法}

核能综合法或核安全法没有涉及或没有展开的 核安全法律制度可通过另行立法来规定, 且不少国 家, 包括部分采取上述两种模式的国家, 都采用了这 种方式. 例如: 在核安全监管制度方面, 南非 1999年 颁布了《国家核监管机构法》, 瑞士 2007 年颁布了 《核安全检查局法》, 日本在福岛核事故以后为集中 核安全监管权于 2012 年通过《原子能规制委员会设 置法》设立了原子能规制委员会; 在辐射防护制度方 面, 俄罗斯 1997 年颁布了《公众辐射安全法》, 我国 台湾地区 2002 年制定了《辐射防护法》; 在实物保 护制度方面, 法国 1980 年颁布了《核材料保护和控 制法》, 韩国 2003 年颁布了《实物保护与辐射应急 法》; 在核应急准备与响应制度方面, 日本 1999 年制 定了《原子力灾害特别应对法》, 我国台湾地区 2003 年制定了《核应急法》; 在核损害赔偿责任制度方面, 制定单行法的国家更多, 如美国 1957 年通过了《普 莱斯一安德森法》(2005 年修改), 法国 1968 年制定 了《核第三方责任法》(1990 年修改), 日本 1961 年 制定了《关于核损害赔偿的法律》(1999 年修改), 加 拿大 1970 年通过了《核责任法》(1985 修改)等.

上述国家中, 美国、日本、瑞士、南非、俄罗斯、 韩国和我国台湾地区都制定了核能领域的综合法一 一原子能法, 而法国、加拿大则制定了独立的核安 全法.

\section{3 核安全法律制度构建的域外经验分析}

综上所述，核安全法律制度的构建既有硬性的
国际公约的原则性要求又不缺乏为实现这些要求的 国际“软法”之详细建议, 而这些要求和建议又被国 家层面的立法实践所“激活”, 从应然状态走向实然 状态. 各国(地区)形式多样的核安全法律制度构建方 式对我国具有重要的启示意义和借鉴价值.

首先，各国都在法律层面对核安全法律制度作 出了安排. 无论是在核能综合法中规定核安全法律 制度还是专门制定核安全法, 抑或是就某项核安全 法律制度进行立法, 上述各国都将核安全法律制度 的构建定位在国家法律这一效力级别上.

其次, 核安全法律制度的构建并非要集中在一 部法律中完成. 从各国核安全法律制度构建或完善 的方式看, 国际要求的八项法律制度可能都被放在 核能综合法中或者核安全法中, 也可能被分别安排 在这两者之中, 但更多的是被分别规定在核能综合 法或核安全法与关于单项核安全法律制度的法律里 面. 换言之, 核能综合法或核安全法都不一定要甚至 也难以全部规定这八项法律制度.

再次，核安全法在制度构建方面体现着“共同但 有区别的原则”。通过对各国核安全法的制度梳理发 现, 各国核安全法的共同点在于对核安全监管制度、 核安全许可证制度、辐射防护制度和许可证持有人的 安全责任制度都有安排, 不同之处表现为各国核安 全法对其他四项核安全制度一一实物保护制度、核应 急准备与响应制度、核安全信息公开制度和核损害赔 偿责任制度的规定与否则因法而异.

最后，较之于在综合性核能法中规定核安全制 度而言, 制定专门的核安全法律会使某些重大关切 的核安全制度如核安全监管、核损害赔偿责任和核应 急准备与响应等得以放大并强化实施. 这对于一般 安全意识相对低下、尚未在核安全领域积累很多经 验、核能事业与法治建设尚处于发展完善中的国家而 言, 意义显得尤为重大.

\section{3 我国核安全法律制度的现状与存在的 问题}

\section{1 我国核安全法律制度的现状}

我国从核工业发展之初就开始重视对核能的监 督管理, 提出了“安全第一, 质量第一”的核安全工作 方针.八十年代初原国家环保局开始辐射环境管理 
工作, 1984 年 1 月 1 日中国加入国际原子能机构, 同 年 10 月 30 日成立国家核安全局, 负责对民用核设施 的监督管理工作. 为了顺应国际原子能机构对民用 核设施进行管理的要求, 1986 年 10 月 29 日国务院发 布了《民用核设施监督管理条例》，规定国家核安全 局对全国民用核设施安全进行监督管理, 制定核安 全法规。这标志着我国开始重视核安全法律制度的 建设.

虽然有关核能与核安全立法的进展较慢, 但随 后的二十多年间国务院相继颁布了九部行政法规, 包括: 《民用核设施安全监督管理条例》(1986 年)、 《核材料管制条例》(1987 年)、《核电厂核事故应急 管理条例》(1993 年)、《放射性同位素与射线装置安 全和防护条例》(1989 年制定, 2005 年修订)、《核出 口管制条例》(1997 年制定, 2006 修改)、《核两用品 及相关技术出口管制条例》 (1998 年制定, 2007 年修 改)、《民用核安全设备监督管理条例》(2007 年)、

《放射性物品运输安全管理条例》(2009 年)和《放射 性废物安全管理条例》(2011 年). 在此期间内, 为了 适应新形势下环境保护和核产业发展的需要, 建立 和完善放射性污染防治法律制度, 第十届全国人 大会常委会于 2003 年 6 月 28 日通过了《放射性污 染防治法》, 使其成为我国核法体系中的唯一一部法 律. 此外, 国家核安全局、环保部、原核工业部、 卫生部、公安部、国防科工局、原电力部、国土资源 部还制定了大量的核安全相关部门规章; 广东、上 海、浙江、吉林等省市还出台了相关的地方性法规和 政府规章.

总体而言, 经过二十多年的努力, 我国基本形成 了核安全法规体系框架, 其调整的范围涵盖了从铀 矿开采到放射性废物处置的核产业链所有环节, 构 建了包括核安全监管制度、许可证制度、辐射防护制 度、实物保护制度、核应急准备与响应制度和许可证 持有人安全责任在内的大部分国际要求中的核安全 制度.

\section{2 我国核安全法律制度存在的问题}

我国虽然已经建立了一套核安全法规体系, 但 在制度构建方面仍然存在诸多不足. 这些不足主要 包括制度构建中法律的缺位、部分核安全法律制度存 在立法空白、部分核安全法律制度规定不明确以及部 分核安全法律制度内容陈旧等.

\subsection{1 制度构建中法律的缺位}

我国没有核能综合法或核安全法等对核安全法 律制度进行统一规定的法律，目前只有一部法律一 一《放射性污染防治法》。该法主要从环境管理/环境 保护的角度对核技术、铀(针)矿、伴生放射性矿开发 利用过程中和核设施场界外与放射性污染相关的措 施作出了规定，涉及辐射防护制度、核应急制度等部 分核安全法律制度，但整部法没有提及“核安全”的 概念, 对重要的核安全法律制度, 如核安全监管制 度、核安全信息公开制度、核损害赔偿制度等也没有 规定. 所以无论是从价值定位还是从制度设计的周 密性来看, 《放射性污染防治法》对核安全法律制度 的构建都具有局限性, 况且该法已经实施 10 年, 可 能要面临修改.

在此背景下，我国核安全法律制度构建的重任 实质上都是由下位的行政法规甚或是效力级别更低 的部门规章来担当的. 比如, 《民用核设施安全监督 管理条例》对核设施安全监管制度、核设施安全许可 制度、许可证持有人的安全责任制度进行了规定， 《核电厂核事故应急管理条例》对核电厂的核应急准 备与响应制度做出了安排. 这样导致的后果是核安 全的各项法律制度之间缺乏统筹协调, 其制定和修 订缺乏可供贯彻的系统性的核安全思想, 制度构建 缺乏体系化的考量和设计 ${ }^{[9]}$. 与其他国家在效力级别 为国家法律的层面上构建核安全法律制度的实践相 比，我国还存在差距.

\subsection{2 部分制度存在立法空白}

我国核安全法律制度还存在的一个较大问题就 是部分重要制度缺乏法律法规的规范, 亦即存在立 法空白. 核损害赔偿制度和核安全信息公开制度就 是其中具有代表性的两项. 首先, 关于核损害赔偿责 任制度，目前只有《国务院关于核事故损害赔偿责任 问题的批复》(2007 年)对核损害赔偿责任主体、赔偿 原则、运营者赔偿数额与财政保证、国家最高补偿限 额等做了简单的规定，没有明确赔偿范围、赔偿程 序、法院管辖和诉讼时效等事项，且已规定的事项过 于原则, 缺乏可操作性 ${ }^{[10]}$. 从严格意义上来说, 该批 复不属于我国《立法法》(2000 年)规定的法律法规的 范畴，换言之，核损害赔偿责任制度存在立法空白. 其次，关于核安全信息公开制度，国务院和环保部虽 然分别颁布了《政府核安全信息公开条例》(2007 年) 
和《环境核安全信息公开办法》(2007 年), 但具体的 核安全信息公开仍没有明确的法律规范. 2011 年 4 月 环保部的颁发《环境保护部(国家核安全局)核与辐射 安全监管核安全信息公开方案(试行)》和《关于加强 核电站核与辐射安全核安全信息公开的通知》同样不 属于我国《立法法》中的法律法规范畴.

\subsection{3 部分核安全法律制度规定不明确}

虽然行政法规和部门规章对我国的大部分核安 全法律制度做出了安排, 但这些法律文件对部分核 安全法律制度的规定仍然存在不明确之处, 其中典 型的例子就是核安全监管制度中监管机构的监管范 围不清晰. 按照《放射性污染防治法》的规定, 核设 施分为民用核设施和军用核设施. 其中民用核设施 依照《民用核设施安全监督管理条例》由国家核安全 局独立行使安全监督权, 军用核设施根据《国防科技 工业军用核设施安全监督管理规定》(1999 年)由国防 科工委(现在为国防科工局)实施统一安全监督. 但这 些法律文件并没有明确定义何为“民用核设施”，也 没有解释什么是“军用核设施”, 从而导致监管实践 中核安全局和国防科工局的监管存在冲突. 比如, 实 践中就出现过原本由核安全局监管的民用核设施在 为民用核能提供生产服务的同时由于接受军事采购, 而被视为“军用核设施”或者“军工核设施”, 进而被纳 入国防科工局的监管范围内的情形. 这种状况的存 在显然有损核安全监管的独立性、权威性和有效性.

\subsection{4 部分制度内容陈旧}

核领域的部分行政法规和大部分的部门规章制 定于我国民用核能发展初期, 即二十世纪八九十年 代，其制度设计直于当时的各种因素. 时至今日，不 论是我国经济社会发展的宏观大背景, 还是我国核 能的发展规模与核能管理体制以及面临的核安全形 势都发生了巨大变化, 但仍有部分核安全法律制度 没有“与时俱进”。例如实物保护制度，国家核安全局 颁发的《核材料管制条例实施细则》(1990 年)规定核 材料实物保护制度由能源部设立在中国核工业总公 司下的核材料管制办公室实施，国防科工委和公安 部相关部门也参与部分工作，但是历经多次政府机 构改革后上述能源部早已不复存在，中国核工业总 公司也实现了政企分开变成现在的中国核工业集团 公司，国防科工委也成为国防科工局. 此外, 实物保
护制度的国际要求已经扩展到核设施，而我国的实 物保护制度并未修缮.一个法律制度，如果跟不上时 代的需要或要求, 而且死死抱住上个时代的只有短 暂意义的观念不放，那么显然是不可取的 ${ }^{[11]}$.

\section{4 我国核安全法律制度的构建与完善}

认识和指出我国核安全法律制度的不足，目的 在于指出构建我国核安全法律制度理想图景的路径 和方法. 本文认为，一方面核安全法律制度的构建是 履行国际义务, 各国的实践对我国具有一定的参考 和借鉴意义，另一方面我国现有的核安全制度体系 这一“本土资源”体现了我国的实际国情，我国核安 全法律制度构建和完善的路径应该体现对这两方面 的综合考虑. 基于此，本文提出以下建议.

\section{1 关于核安全法律制度构建与完善的立法必要 性与紧迫性}

我国核安全法律制度存在上述问题的最主要原 因在于制度构建缺乏顶层设计。虽然我国有一套综 合的核安全法规体系，但它不是一个整体，而是分散 在具有不同行政和司法级别的各类文件中，需要统 一和合并 ${ }^{[12]}$. 具体而言，实质上构建我国核安全法律 制度的法律文件处于“群龙无首”状态，制度体系缺 乏上位法的支撑. 为此, 迫切需要通过立法在法律层 面上系统化统筹构建我国核安全法律制度，并在立 法过程中对现有制度规定不明确、制度内容陈旧之处 进行完善. 这既是我国核安全法律制度构建与完善 的现实出路同时又与各国的做法相一致。此次核安 全法被纳入 《十二届全国人大常委会立法规划(共 68 件)》中的第二类项目证明我国已经意识到并开始重 视通过立法来构建核安全法律制度，当务之急是加 快推动立法进程.

\section{2 关于核安全法律制度构建与完善的立法模式 选择}

我国核安全法律制度构建应选择多元化立法路 径. 如上文所述, 虽然国际规范文件的要求主要归纳 为八项法律制度，但每一项制度的内容都非常复杂， 试图通过一部法律对这些制度进行全面规定可能存 在难度. 上述大多数国家都选择通过制定多部法律, 即选择了多元化立法路径来分别构建这些制度. 对 
我国而言, 如寄希望于在一部法律中完成所有核安 全法律制度的构建也很困难，原子能法立法起草历 经二十多年至今未获通过其原因也与此不无关系. 国务院于 2012 年 10 月通过的《核安全规划》提出要 同时推进核安全法和原子能法的立法研究工作, 正 是对多元化立法路径的肯定. 接下来需要研究和解 决的问题是要明确这两部法律的定位, 使其在核安 全法律制度构建方面做到各自“有所为有所不为”。

\section{3 关于核安全法立法的制度选择与完善}

在多元化立法模式下，需要界定核安全法在 制度构建方面的“作为”与“不作为”, 即在目前的情况 下核安全法应当规定哪些法律制度, 可以规定哪些 制度.上述各国的核安全法都对核安全监管制度、 核安全许可证制度、辐射防护制度和许可证持有人的 安全责任制度进行了规定. 其背后的逻辑是：政府 对核安全实施独立监督势必要求其设立核安全监 管机构专司其职, 而核安全许可制度作为监管机构 实施监管的必备手段通常是其职权的一部分; 监管 机构的监管离不开许可证持有人的配合, 许可证持 有者的安全责任制度则是从被监管者的角度保障许 可证的条件得到落实; 而辐射防护制度又是放射性 物质操作和设施运行的必不可少的前提条件 ${ }^{[7]}$. 换言 之, 这四项制度是实现核安全监管的必不可少的基 本制度, 亦即从理论上来讲核安全法如不规定这四 项制度将难以完成其基本的核安全目标. 因此, 建议 我国核安全法立法也应规定这四项制度. 而实际上 如上文所述这四项制度已经在我国现有的核安全法 规中都有涉及, 对核安全法立法来说已经具备现实 基础.

除了这四项制度以外, 由于各国核安全法对其 他法律制度是否进行规定的做法不一致, 我国是否 应该在核安全法中对这些制度进行规定则值得探讨. 笔者认为, 首先, 我国核安全法立法可以规定核应急 准备与响应制度和核安全信息公开制度. 理由是《放 射性污染防治法》第二十六条虽然已对核应急准备与 响应制度进行了规定, 但该规定较为原则. 核安全法 立法时在与《放射性污染防治法》保持协调并对其他 下位条例和规章进行梳理的基础上, 对其进行规定 难度并不大, 而且可以使核安全法的内容更加完整, 因为核安全的定义既包括对核事故的预防也包括对
事故后果的缓解. 而核安全信息公开制度是时代趋 势、是增加公众对核能可接受性，增强对核安全信心 的制度安排, 也是我国正在推动和尝试的新制度. 将 其纳入核安全法能够彰显我国核安全监管的透明性, 成为我国核安全法的亮点之一.

其次，建议实物保护制度和核损害赔偿制度可 以通过核能综合法或者单独立法来规定. 这是因为 实物保护是从安保的角度对核材料或设施实施保护 的措施, 国际原子能机构的安全标准系列文件中不 包括安保的内容, 国际原子能机构的《核法手册》也 将其与核与辐射安全区别开来, 并将其与核不扩散 放在同一部分. 而核损害赔偿制度因其内容较复杂, 各国通常对其单独立法或者在核能综合法中进行原 则性规定再通过单独立法具体细化，我国《国务院关 于核事故损害赔偿责任问题的批复》也要求在起草 《中华人民共和国原子能法(草案)》时对该制度进行 明确规定.

应当指出的是, 无论是核安全法还是其他法律 在制度构建中都需要对上文指出的我国目前的核安 全法律制度存在的不足之处进行梳理并完善, 包括 考虑对国际经验的借鉴, 对我国核安全工作实践的 调研和总结, 以及加强相关部门之间的协调.

\section{5 结论}

历史经验表明只有重视核安全才能减低核事故 发生的概率，保障核能健康发展. 本文发现：通过构 建核安全法律制度来保障核安全是国际社会与各国 的共识和实践; 各国在构建国际要求的八项主要核 安全法律制度时采用了不同的立法模式; 我国作为 在建核电站数量最多的国家和未来的核电大国在此 方面的工作仍然滞后, 核安全领域的专门法律至今 阙如, 现有核安全法律制度存在立法空白、规定不明 确、内容陈旧等诸多不足.

为此, 本文认为: 通过制定法律来构建和完善我 国的核安全法律制度势在必行; 核安全法律制度构 建应选择多元化立法模式; 核安全法在制度构建方 面应重点构建和完善核安全监管、核安全许可、辐射 防护和许可证持有人的安全责任这四项制度，此外 可以考虑规定核应急准备与响应以及核安全信息公 开制度. 
参考文献

1 张力. 核安全: 回顾与展望. 中国安全科学学报, 2000, 10: 15-20

2 International Atomic Energy Agency. IAEA Safety Glossary: Terminology Used in Nuclear Safety and Radiation Protection. 2007 ed. Vienna: International Atomic Energy Agency, 2007. 149

3 王铁崖. 国际法. 北京: 法律出版社, 1995. 332

4 布拉德布鲁克 A J, 奥汀格 L L, 编. 曹明德, 邵方, 王圣礼, 译. 能源法与可持续发展. 北京: 法律出版社, 2005. 52

5 高宁. 国际原子能机构与核能利用的国际法律控制. 北京：中国政法大学出版社, 2009.89

6 International Atomic Energy Agency. Governmental, Legal and Regulatory Framework for Safety. IAEA Safety Standards Series No. GSR Part 1. Vienna: International Atomic Energy Agency, 2010. 16-32

7 Stoiber C, Baer A, Pelzer N, et al. Handbook on Nuclear Law. Vienna: International Atomic Energy Agency, 2003. 35-41

8 OECD. Nuclear Legislation in OECD Countries. Korea: Regulatory and Institutional Framework for Nuclear Activities, 2009

9 邓禾, 夏子耀. 中国核能安全保障法律制度与体系研究. 重庆大学学报(社会科学版), 2012, 18: 26-32

10 落志筠. 中国大陆核损害赔偿法律制度的完善. 重庆大学学报(社会科学版), 2012, 18: 42-49

11 博登海默 E, 著. 邓正来, 译. 法理学: 法律哲学与法律方法. 北京: 中国政法大学出版社, 2004. 340

12 International Atomic Energy Agency. Integrated Regulatory Review Service (IRRS) Mission for China. Beijing: International Atomic Energy Agency, 2010. 14-42

\title{
Construction and improvement of the nuclear safety legal systems in China: A preliminary analysis
}

\author{
HU BangDa ${ }^{1}$, WANG $\operatorname{Jin}^{1} \&$ WU YueLei ${ }^{2}$ \\ ${ }^{1}$ Law School, Nuclear Policy and Law Center, Peking University, Beijing 100871, China; \\ ${ }^{2}$ Nuclear and Radiation Safety Center, Ministry of Environmental Protection, Beijing 100089, China
}

The nuclear safety legal system is an essential instrument to ensure the safe development of nuclear energy. The international requirements and recommendations for the construction of nuclear safety legal systems can be mainly summarized to eight systems. Many countries have complied with these recommendations and requirements, and have constructed those systems through enacting laws, while China's construction of nuclear safety legal systems has many deficiencies. This situation needs to be improved. For this purpose, we suggest that (i) it is necessary and urgent to construct and improve our nuclear safety legal systems by legislation; (ii) the legislation should be diversified; and (iii) the nuclear safety law should provide the nuclear safety regulatory system, the licensing system of nuclear safety, the radiation protection system and the license holder's safety responsibility system, and take into consideration the nuclear emergency preparedness and response system and the nuclear safety information disclosure system.

nuclear safety, legal system, legislation, regulatory body, information disclosure

doi: $10.1360 / 092013-1182$ 